\title{
Resistance to extinction as a function of reinforcement schedule: A within-subject design
}

\author{
A. GRANT YOUNG, W. R. FAVRET, and J. B. KEYES \\ Louisiana State University, Baton Rouge, Louisiana 70803
}

\begin{abstract}
Sixty-four male albino rats were trained to run a straight runway. Half of the subjects were trained on a continuous reinforcement schedule (CRF) and half on a partial reinforcement schedule (PR). On reinforced trials, a lever was introduced into the goalbox and the subject was allowed to make 10 discrete trial leverpresses for sucrose. The lever was not introduced into the goalbox on nonreinforced trials. The subjects were trained under either a CRF or PR leverpress schedule. Upon completion of acquisition half of the subjects in each subgroup were extinguished in the runway and the other half were extinguished in the goalbox on the lever. Results showed that for subjects extinguished on the lever the partial reinforcement effect (PRE) was a function only of the lever reinforcement schedule and was independent of the runway reinforcement schedule. However for subjects extinguished in the runway, PR runway-trained subjects receiving CRF leverpress training were more resistant to extinction than were PR runway-trained subjects receiving PR leverpress training.
\end{abstract}

The partial reinforcement effect (PRE), increased resistance to extinction following intermittent reinforcement training (PR) as compared to continuous reinforcement training (CRF), is a well established phenomenon (Lewis, 1960).

A number of experiments, using a within-subject design, have shown that PRF training under one set of external stimulus conditions and CRF training of the same response under a different set of external stimulus conditions results in increased resistance to extinction when subjects are extinguished under either set of external stimulus conditions (Brown \& Logan, 1965; Rashotte \& Amsel, 1968; Young \& Costelloe, 1974). For example, in the Young and Costelloe study rats were trained to leverpress with the houselight ON (or OFF) as the differential external stimulus conditions. The subjects received either (CRF) (ON)-PRF (OFF) or CRF (OFF)-PRF (ON) training schedules followed by extinction either with the house light $\mathrm{ON}$ or the light OFF. Results showed that the PRE did not become differentially associated with either external stimulus condition.

These studies are in agreement that after training as described above, subjects show what has been called the generalized partial reinforcement effect (GPRE). That is, PR-training increases resistance to extinction under either set of external stimulus conditions even though one set of stimuli has been associated with PR and the other set of stimuli has been associated with CRF.

These studies suggest that the PRE may be "response specific," which is to say that whatever causes the PRE becomes attached in some way to the stimuli produced by the instrumental response. This hypothesis is similar

This research was supported in part by a grant from the University Council on Research, L.S.U., to the first author.

J. B. Keyes is now at the Division of Psychology, John F. Kennedy Institute, Baltimore, Maryland 2025. to, if not identical with that of Mowrer (1960), and would predict that in the experiments cited above, since the same (leverpress) response was made under both external stimulus conditions, and since the PRE was attached to the response-produced stimuli, that all groups should show the GPRE, which was the result obtained.

Additional support for this hypothesis was demonstrated in a study (Young, Hale, \& Fuselier, 1974) in which rats were trained to run a straight runway and to leverpress in an operant chamber. The subjects were trained on a CRF or PR schedule in one apparatus, switched to the other apparatus, subdivided, and trained on either a CRF or PR schedule. The subjects were then extinguished in the runway or on the lever. Results showed that resistance to extinction of either response was a function of the training reinforcement schedule for that particular response only, and was independent of the reinforcement schedule received in the training of the other response. Thus, no GPRE was obtained when the response under CRF condition was extinguished.

In the above experiment, two different experimental situations (runway and operant chamber) were used with each situation being associated with a different response. The present experiment was conducted to determine if the same results would be obtained when there is PR training of one response and CRF training of a different response within the same general experimental situation.

\section{METHOD}

\section{Subjects}

The subjects were 64 naive male albino rats, $150-175 \mathrm{~g}$ in weight at the start of the experiment.

\section{Apparatus \\ The apparatus was a straight Plexiglas runway 60 in. long, $4 \mathrm{in.} \mathrm{high,} \mathrm{and} 4 \mathrm{in}$. wide, including the startbox (6-3/4 in. long)}


and goalbox (10 in. long, and 5-3/8 in. wide). The runway had a grid floor and guillotine doors separated the start-and goalboxes from the runway. A Plexiglas retrace door was located $9 \mathrm{in}$. from the goalbox. Fitted on the end wall of the goalbox was a retractable lever and a liquid dipper which dispensed $.01 \mathrm{ml}$ of a $40 \%$ sucrose solution. Raising the startbox door started a timer, calibrated in tenths of a second, which was stopped when the subject passed through a photobeam at the entrance to the goalbox.

\section{Procedure}

The subjects were randomly selected from the LSU colony and were placed in individual cages on a food deprivation schedule of $10 \mathrm{~g}$ Purina Chow every $24 \mathrm{~h}$. Water was available in the cages at all times and subjects were fed approximately 10 min after each experimental session.

From Days 4-8 subjects were handled in pairs for 5 min each day, and on Days 9-12 subjects were given magazine training on a VI $30-\mathrm{sec}$ schedule. Experimental periods consisted of 20 presentations of the dipper.

On Day 13 all subjects were conditioned to leverpress and allowed to make 50 reinforced responses. On Day 14 subjects were given five continuously reinforced runway runs where each run was followed by 10 continuously reinforced leverpresses. A discrete trial procedure was used and the lever, which required $4 \mathrm{sec}$ to retract and extend fully, was inoperative during retraction.

Acquisition training began on the following day. Each group of subjects was randomly subdivided, creating four treatment groups: CC, CP, PC, and PP. For the group designations, the first letter indicates reinforcement schedule in the runway and the second letter indicates reinforcement schedule on the lever. Thus, subjects in the group $\mathrm{CP}$ received continuous reinforcement in the runway and partial reinforcement on the lever. Acquisition training consisted of ten alley runs daily with a 15 -sec intertrial interval and continued for 10 days. Both runway and leverpress latencies were recorded during acquisition. For PR-trained subjects in either the runway or on the lever, the reinforcement schedule was a VR 2 with the restriction that not more than three consecutive alley runs or leverpresses were reinforced or nonreinforced.

Upon completion of acquisition, the four groups were randomly subdivided. Half of the subjects in each group were extinguished in the runway, and the other half were extinguished on the lever. Thus, in extinction there were eight experimental groups: CC-L, CP-L, PC-L, PP-L, CC-R, CP-R, PC-R, and PP-R. The third letter of the group designation indicates whether extinction was on the lever (L) or in the runway (R).

Extinction sessions on the lever were $10 \mathrm{~min}$ in length and continued for 3 days. Extinction sessions in the runway consisted of five runs daily for 5 days, and total latency for the five trials on each day was recorded. On any trial, if the subject failed to break the photobeam within $30 \mathrm{sec}$ the timer was stopped, the subject was removed from the runway and returned to the holding cage to await the next trial, and a latency of $30 \mathrm{sec}$ was recorded. Thus, the maximum possible latency for any block of five trials was $150 \mathrm{sec}$.

\section{RESULTS AND DISCUSSION}

The total number of responses made by each subject extinguished on the lever was recorded and results showed that more responses were made by Group PP-L, followed in order by Groups CP-L, PC-L, and CC-L. These data were subjected to an analysis of variance which showed that the main effect of lever reinforcement schedule was significant beyond the .01
Table 1

Mean Number of Leverpresses in Extinction

\begin{tabular}{cc}
\hline Group & $\begin{array}{c}\text { Mean Number } \\
\text { of Responses }\end{array}$ \\
\hline CC-L & 91.75 \\
CP-L & 183.63 \\
PC-L & 101.38 \\
PP-L & 184.63 \\
\hline
\end{tabular}

level. Group comparisons showed no significant differences between Groups PP-L and CP-L, or between Groups PC-L and CC-L. The main effect of runway reinforcement schedule and the runway by lever interaction were not significant at the .05 level. The mean number of leverpresses in extinction for all groups is shown in Table 1.

The total latency for each block of five trials in runway extinction was recorded and converted to reciprocals. Results showed greater resistance to extinction by Group PC-R, followed in order by Groups PP-R, CC-R, and CP-R. These data were subjected to an analysis of variance with repeated measures and results showed that the main effect of runway reinforcement schedule was significant beyond the .01 level. Thus, PR runway-trained subjects were more resistant to extinction than were CRF runway-trained subjects. The main effect of leverpress reinforcement schedule was significant beyond the .05 level, and CRF leverpress-trained subjects were more resistant to extinction in the runway than were PR leverpress-trained subjects. The Lever by Runway interaction was significant beyond the .05 level, and comparisons showed that the difference between Groups PC-R and PP-R was significant beyond the .01 level, while the difference between Groups CC-R and CP-R was not significant at the .05 level.

The main effect of trials and the Trials by Runway interaction were significant beyond the .01 level. These findings indicate respectively, that running speeds decreased across trials and PR-trained subjects extinguished significantly slower than CRF-trained subjects. Mean running speeds in the runway during extinction for all groups is shown in Table 2.

Results, thus, show that PR lever-trained subjects were more resistant to extinction on the lever than were CRF lever-trained subjects, and extinction on the lever was independent of runway reinforcement schedule. These data are in agreement with other studies (Young \& Costelloe, 1974; Young, Hale, \& Fuselier, 1974).

Results also indicate that extinction in the runway for $\mathrm{CRF}$ runway-trained subjects is independent of leverpress reinforcement schedule; however, extinction in the runway for PR runway-trained subjects is not independent of leverpress reinforcement schedule. Although this last result was unexpected, the results are clear that there is no transfer of the PRE from one 
Table 2

Mean Speed of Responding in Extinction

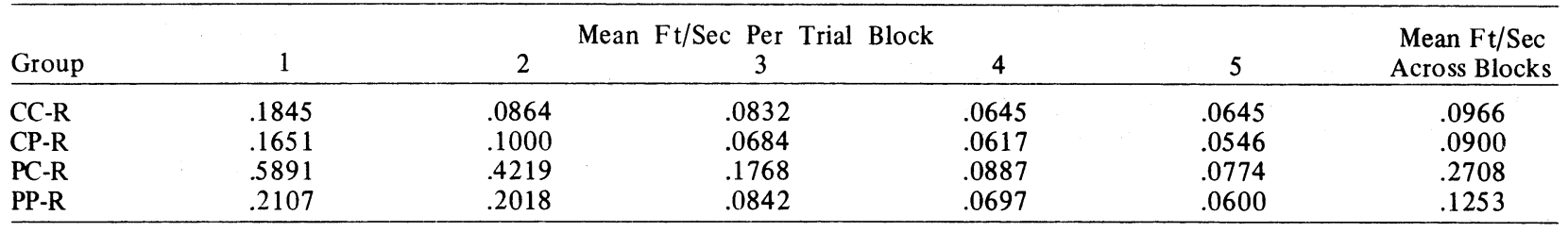

response to another even in the same general experimental situation.

\section{REFERENCES}

Brown, R. T., \& Logan, F. A. Generalized partial reinforcement effect. Journal of Comparative and Physiological Psychology, $1965,60,64-69$.

Lewis, D. J. Partial reinforcement: A selective review of the literature since 1950. Psychological Bulletin, 1960, 57, 1-28. Mowrer, O. H. Learning theory and behavior. New York: Wiley, 1960.
Rashotte, M. E. \& Amsel, A. The generalized PRE: Within-S PRF and CRF training in different runways, at different times of day, by different experimenters. Psychonomic Science, 1968 $11,315-316$.

Young A G \& Costelloe, C. Resistance to extinction as a function of partial reinforcement and external stimuli: A within-S design. Bulletin of the Psychonomic Society, 1974, 3, 191-192.

Young, A. G. Hale, P. A. \& Fuselier, G. D. A within-S test of the response and specificity of the PRE. Bulletin of the Psychonomic Society, 1974, 3, 437-439.

(Received for publication October 23, 1974.)

\title{
The effect of septal lesions on acquisition of a classically conditioned fear response
}

\author{
MELVIN L. GOLDSTEIN \\ Indiana University at Kokomo, Kokomo, Indiana
}

\begin{abstract}
Septal lesions were placed in rats and the animals were then tested with two variations of the classical conditioning fear response. One variation involved the inclusion of an exploration procedure before the test session, which was designed to reduce response conflict between crouching, or freezing, and hurdle jumping. The other variation was a "no-exploration" condition. These two variations are assumed to be analogous to one-way avoidance conditioning and to two-way shuttlebox avoidance conditioning, respectively. Septal lesions reduced the level of performance under the "exploration" condition. The performance of septal-lesioned animals did not differ significantly from normals under the "no-exploration" condition.
\end{abstract}

The facilitative effects of septal sesions on acquisition during active avoidance conditioning were first reported by King (1958). Septal-lesioned animals were found to

Preparation of this report was supported, in part, by Grant 26-631-32 and by summer faculty fellowships awarded by the Indiana University Office of Research and Advanced Studies.

Charles Borneman, Jr. made the drawings. The writer wishes to express his appreciation to his wife, Daidee, for her patience and helpful comments. Patty Ward typed the manuscript. perform better than normals during acquisition, as measured by trials to a learning criterion.

These results were first replicated by Krieckhaus, Simmons, Thomas, and Kenyon (1964). They reported shorter avoidance response latencies, and a larger proportion of avoidance responses, for septal lesioned animals than for normals. The septal facilitative effect has been replicated many times (cf. Grossman, 1973; Fried, 1972). 